

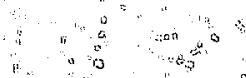
the Uniled Stath Government. Neither the United States nui y, United Stares Atomic Energy Commistion, nor any of their employes, hor any of their eontrictors, subontractots, or their. imployecs, makes any wamanty, express' or.jmptied, of assumes

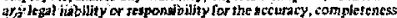
d userulness of any'teforibation, apoliratus, product of process Cisclosed oi nepres disclosed, of represents that its un would not inlringe privately

National Technical Information Service 1.S. Department of Commerce "5285 Port Roya1 Roađ'

\section{Springfield, Vifginia 22151}

Price: Printed Copy \$ Mi Microfiche" $\$ 1.45$

6

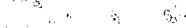


TID-4500, UC-38

Engineering and

Equipment

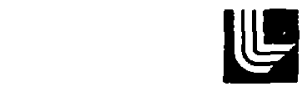

LAWRENCE LIVEFMORE LABORATORY

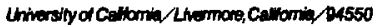

UCRL-51709

\section{ABSOLUTE SPECTRAL MEASUREMENTS OF ILLCTRONS FROM HIEH-INTENSITY, NONREPETITIVELY PULSED SOURCES}

K. G. Tirsell

L. G. Multhauf

MS. date: December 16, 1974

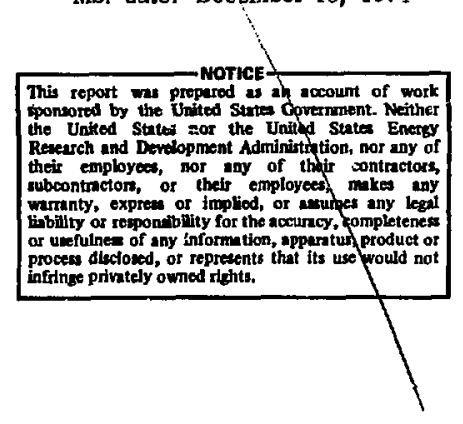

Hegne

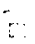




\title{
ABSOLUTE SPECTRAL MEASUREMENTS OF ELECTRONS FROM HIGH-INTENSITY. NONREPETITIVELY PULSED SOURCES
}

\begin{abstract}
Abutract
We discugs the design and calibration of electron spectrometers applicable to spectral measurements of high-intensity, nonrepetitively pulsed sources. The main emphasls is on flat permanentmagnet apectrometers that enable one to measure several spectral points aimul-

taneously. We discuss low-unerty electron detectors ultable for use in these spectrometers as well as aystems to record detector output curreni. Callbra* tion procedures and resulte are presented for the ailicon detectors we have found to be moat effective.
\end{abstract}

\section{Introduction}

Most electron spectrum measurements are made on low-Intensity sources for which conventional counting techniques are approprlate. Such methods are not applicable to spectral measurements of hlgh-intenslty, nonrepetitively pulsed sources. In this report we will discuss electron spectrometur destgns and calibration techniques that have evolved during a series of dlagnostics experlments for which the sourcas were nonrepetitively pulsed and required one or two completely calibrated spectrometers for each submicrosecond radlation burst. These spectrometers are of great value in the meagurement of electrons emanating from a laser-produced plusma. We are presently conducting a serles of laser plagma electron measurements with a spectrometer of the latest design. We will also outline characteristics of associated high-current electron detectors and pulge recording systems.

\section{Electron Spectrometer Deaign}

Most of the electron apectrometer discussed in the literature have been designed to analyze magnetlcally electrone emitted from amall radioactive sources. ${ }^{1}$ For this application, the source must usually be located in the magnetic field, often ourrounded by the apparatus. One thereby obtains the necessary high transmission (where transmission refers to the fraction of emitted electrons incident on a detector) with good enurgy resolution. Transmission values as high as $20 \%$ with better than $2 \%$ energy resolution have been obtained 

using large, iron-free, tol oidal
designs.

These designs are not appropriate for the case under consideration, however, in which the spectrometer is placed at a distance from the source, e.g., when intrusion in:o the source region interferes with an incident beam or other experiments, or when the spectrometer detectors must be well shielded from other radiations produced by the source. Some desjgns suitable in this case are described below. In choosing a design, one must take into account the defining electron-aperture dimengions, the source size, and the source-to-aperture distance to optimize the spectrometer transmission and resolution.

\section{UNIFORM - FIELD DESIGNS}

The simplest, and for many applications best, spectrometer design consists of an electron aperture, a flat uniformfield magnet, and an array of detectors situated on a focal plane. Spectrometers using this design have several important advantages over those requiring a nonuniform field. They are easily constructed and can be made relatively compact. The magnetic fieid can be accurately measured and, hence, the performance accurately predicted. Also, Geverai spectra! points can be obtained for a single source pulse, the spectrum belng registered elther with an array of detectore or photographically (though in the latter case, with diminished absolute-intensity accuracy).

Fiat permanent-magnet spectrometers have been designed in both $90^{\circ}-$ and $180^{\circ}-$ fo using configurations. The design choice is dependent on sourcespectrometer geometry for the intended application. We have used both for single-pulse fieli measurements. As can be seen in Fig. 1, the base resolving power of a $180^{\circ}$ spectrometer is strongly dependent on the electron aperture width, but is relatively insensitive to the source size. Hence, this clesign is particularly useful when observing a large source with adequate intensity to permit a small entrance aperture. The $180^{\circ}$-focusing spectrometer shown in Fig. 2 was constructed using ceramic pole pieces and used on an experiment to measure electron energieg from 0.3 to $4 \mathrm{MeV}$.
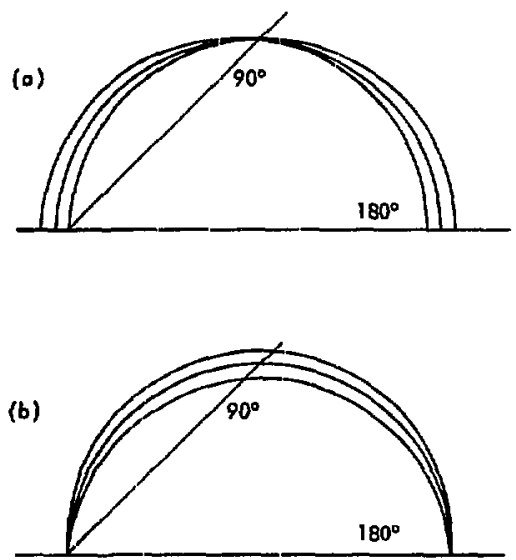

Fig. 1. Focusing characteristics of flat election spectrometers. The magnetic field is directed into the page in each case. (a) Relatively wide entrance aperture with no incident beam divergence. (b) Relatively narrow entrance aperture with a $4^{\circ}$ incl dent beam divergence. 


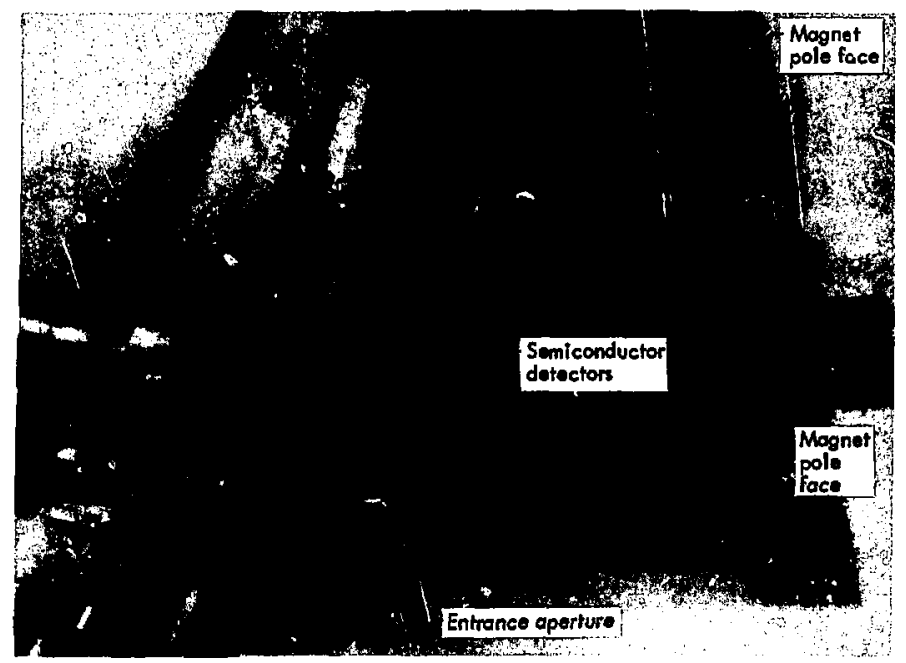

Fig. 2. Electron spectrometer $\left(180^{\circ}\right.$ focusing $)$ with ceramic magnet pole pieces and silicon detectors.

An example of a $90^{\circ}$ assembly is shown In Fig. 3. Fole pieces of "plastiform" and iron were appropriately designed to obtain a field that rapidly increases near the entrance aperture from zero to the design value, thus minimizing the effects of fringing fields. Good field uniformity from the entrance to the detector plane is required to insure predictable spectrometer performance, As shown in Fig. 1 , the base resolving power for $90^{\circ}$ focusing is sensitive to the beam divergence at the aperture, but is insensitlve to the aperture size. Thus, $90^{\circ}$ focusing is superior when the source-to-iperture distance is large. An additional advantage of $90^{\circ}$ over $180^{\circ}$ focueing stems from the shorter electron path lengths, which result in a smaller beam divergence across the magnet gap.

The main disadvantage of uniformfield spectrometers is, of course, that focusing occurs in only one dimension.

\section{DOUBLE - FOCUSING SPECTROMETERS}

A variety of double-focusing spectrometers have been designed to increast system transmission without loss of base resolving power ${ }^{1}$ (or to decrease detector dimensions and thus improve the rise time of an output pulse). Such spectrometers have several disadvantages over uniform-field designs (a) they are more difficult to construct, (b) their performance is harder to calculate, and (c) 


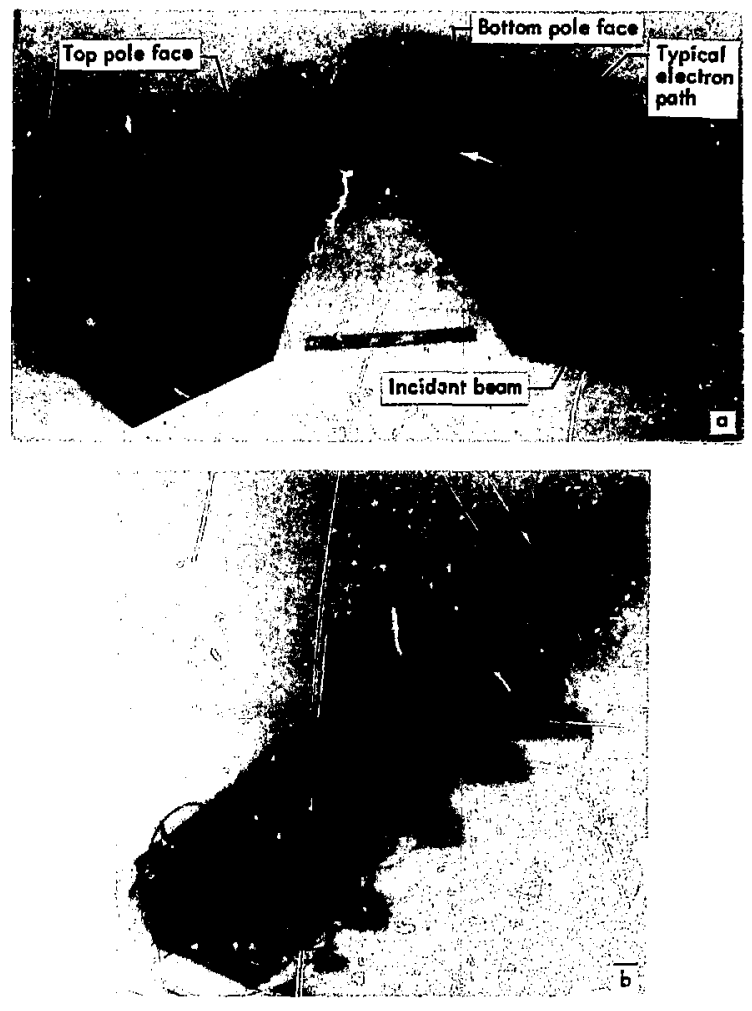

Fig. 3. Electron spectrometer $\left(90^{\circ}\right.$ focusing). (a) Magnet. (b) Associated detector array.

generally only one spectrum point can be obtained per source pulse.

A natural extension of the uniformfield design would involve shaping the fringe field for second-order focusing in the median plane. A carefuliy shaped inhomogeneous field is required for higher-order double focuaing. An exam- ple of a double-focusing spectrometer suitable for electron energies below $1 \mathrm{MeV}$ is a design with a field that varies as $(\mu)^{-1 / 2}$ in the vicinity of $\rho_{0}\left(\rho_{0}\right.$ being the radius of curvature of the central electron path). Such a field can be obtained using, for example, two concentric solenoids or properly shaped pole 
pieres, ' The base resolving power of this design in relation to that of a flat spectrometer is a lactor of 2 lass sensitive to source and detector dimensions and is less sensitive to aperture dimensiuns; in fact, it may be made very insensitive to the aperture width in one dimensinn.

\section{Spectrometer Response Functions}

Energy-response functions for spectrometers of the designs shown in Figs. 2 and 3 have been measured using 150-keV to 4-MeV electron beams at the National Bureau of Standards and 30- to 100-keV electron beams at LLL. Results are in good agreement with -asponse functions calculated using our ray-tracing design code. The code is discussed in detail in Appendix A. The corie wil! also fold in an input-electron spectr uin, which is useful for predicting detector output values, Using calculated response functions and values if measured detector output charge, we can accurately generate a source-electron spectrum.

\section{Electron Detectors}

Several types of low-energy electron detectors suitable for use in magnetic spectrometers bave been developed. They include silicon diodes, anthracene or plastic scintillators coupled to pluotomultipliers, plastic scintillators coupled to photodiodes, and Faraday cups. Some of their more significant characteristics are listed in iable 1.

\section{SILICON DETECTORS}

Silicon semicondurtor detectors are very useful for making electron measurements because of their small volume, insensitivity to magnetic fields, low electron reflectivity (about $10 \%$ from 50 to

\footnotetext{
Feference to a company or product name does not imply approval or recommendation of the product by the University of Callfornia or the U.S. Atomic Energy Commission to the exclusion of others that may be suitable.
}

$400 \mathrm{keV}),{ }^{2}$ and accurately measured electron-ionization energy. ${ }^{3}$ Also, their output charge is linearly related to the energy input uver a wide dynamic range, and the absorbed electron energy can be accurately measured experimentally from pulse-height distributions obtained using monoenergetic incident electrons.

There are three silicon detectors that hava been widely used for electron detection: lithium drifted, surface barrier, and double-diffused $p-i-n$. Lithiumdrifted devices are commonly used to detect high-energy charged particles. They can be made relatively thick (as thick as several millimeters\}, giving them a low capacitance and high energy resolution (when cooled to reduce leakage currents). However, their dead layers arc generally thicker than are those of ot:ier silicon detectors. 
Table 1. Detectors.

\begin{tabular}{|c|c|c|c|c|c|}
\hline Detector system & $\begin{array}{l}\text { Rise time } \\
\text { (nsec) }\end{array}$ & $\begin{array}{l}\text { FWHM } \\
\text { (nsec) }\end{array}$ & $\begin{array}{l}\text { Charge } \\
\text { grin at } \\
100 \mathrm{keV}\end{array}$ & $\begin{array}{l}\text { Peak lineas } \\
\text { current } \\
\text { (A) }\end{array}$ & $\begin{array}{l}\text { Input electron } \\
\text { rangf, } \\
\text { (sec })\end{array}$ \\
\hline Faraday Cup ${ }^{a}$ & $<30$ psec & $<60$ psec & $\sim 1$ & Very high & $-10^{2 b}$ to $10^{19}$ \\
\hline Fluor (NE-111) & 0.35 & 1.31 & & & 10 \\
\hline $\begin{array}{l}\text { Photodiade } \\
\text { (ITT FW 14) }\end{array}$ & $<0.3\}^{0.46}$ & $<0.4\}^{1.4}$ & 40 & 60 & $10^{\circ}$ \\
\hline Fluor (NE-111) & 0.35 & $1.3\}$ & $<10^{a}$ & $100 \mathrm{~mA}$ to $1 \mathrm{~A}$ & 1 to $9 \times 10^{5}$ \\
\hline $\begin{array}{l}\text { Photomultip'ier }{ }^{d} \\
\text { (RCA C31024) }\end{array}$ & $1.6 ? 1.64$ & $3.6\}^{3.6}$ & & JUO $\mathrm{BAC}$ CO JA & \\
\hline $\begin{array}{l}\text { Silicon } \\
\text { bias } \\
=\left(600 \mathrm{~mm}^{2}\right)\end{array}$ & 1 & 1.5 & $2.5 \times 10^{4}$ & 10 & 1 to $6 \times 10^{6}$ \\
\hline $\begin{array}{l}\text { Silicon at } 1000 \mathrm{v}^{\mathrm{e}} \\
\left(150 \mathrm{~mm}^{2}\right)\end{array}$ & 5 & 7 & $2.5 \times 10^{4}$ & 10 & 1 to $3 \times 10^{7}$ \\
\hline \multicolumn{6}{|c|}{$\begin{array}{l}\mathrm{a}_{\text {See Ref. }} 10 . \\
\mathrm{b}_{\text {If }} \text { used with a charge sensitive amplifier. } \\
{ }^{c} \text { See Rer. } 7 . \\
{ }^{d} \text { See Ref. } 8 .\end{array}$} \\
\hline
\end{tabular}

Silicon surface-barrier detectors are now available in thicknesses as great as $5 \mathrm{~mm}$ (the $\mathrm{r} r$ gge of a $2-\mathrm{MeV}$ electron). They can be ootained with thin, front, dead layers $\left(0.05 \mathrm{mg} / \mathrm{cm}^{2}\right.$ aluminums) and good signal-to-noise performance, A. cooled detector should be especially useful at low electron energies. Disadvantages of surface-barrier detectors include high sensitivity to light and low breakdown bias voltuge (hence, a lower linear output current than either lithium-drifted or double-diffused detectors). A further consideration is that the effect of a slow charge collection from weak field regions has not been well documented. If sharge collection is slow compared to the detector output-charge integration time, accurate detector calibration becomes difficult. In the counting mode, a period of one to several micraseconds $i$, normally used to integrate the detector output current generated by an individual electron. With sush a time constant, measured pulseheight distributions are not greatly affected by slew charge collection.

Double-diffured siliccñ $p-i-n$ detectors have been developed epecificaily for singlo-pulse field applications requiring high linear output currents ( $210 \mathrm{~A}$ ) and reasonably fast response times $(2-$ to 10-nsec rir a times'. 4 They can be produced with thin entrance windows (equivalent to 0.2 to $0.5 \mu \mathrm{m}$ of undepieted silicon), so that the fraction of input electron energy absorbed by the active volume wiil be large. We have measured the electron energy absorbec in p-i-n detectors at NBS and LLL (incident electron energies from $15 \rho \mathrm{keV}$ to $4 \mathrm{MeV}$ and from 50 to $\mathrm{i} 00 \mathrm{keV}$, respectively). These measurements are discussed in detail in Appendix B. Experi mental results for detectors thicker than an electron range are in agreement with calculations of Berger and Seltzer ${ }^{5}$ and with those of Brown. ${ }^{2}$ 
Time-response characteristics of $p-:-n$ deteriors b.l."e heen measured using the Edgerton, Germeshasuen and Griev Linac (Senta Earbara)." The rise time is roughly proportional to the square root of the detector area; therefore, time response can be improved in spectrometerr applications at the expense of output pulse amplitude.

ANTHRACENE AND PIASTIC SCINTILLATORS COUPLED TO PHOTOMULTIPLIERS

Another high-gain detector that can be use $f$ in electron spectrometers consists of a low-Z scintillator coupled to a photomultiplier tube. The output of this detector is somewhat nonlinear at low energies. However, as in the case of silizon detectors, efficiencies can be meagured experimentally with counting techniques.

Anthracene and plastic scintillators have similar properties. Compared to plastic, anthracene has a greater light output, but longer decay time. A bare anthracene crystal mounted directly on a photomultiplier tube can be used down to, and perinaps below, 5-keV electron energy, provided that the crystal is properly cleaved and the combination is cocied to reduce the noise level and prevent sublimation of the crystal in vacuo. ${ }^{6}$ (A bare scintillator is, of course, very lightsensitive and must be shielded to prevent background signals, ) At present, the best time response is obtained using an NE-111 plastic fuor ${ }^{7}$ coupled to an KCA $-31024^{8}$ or an Ampers. Pm2106 phototube (see rable 1;.

\section{FLUUR-PHOTODIODES}

A plastic scintillator has a relatively good time response that is degraded when it is coupled to a photomultiplier tube. If high gain is not needed, the scintillator can be coupled to a planar phorodiode that will not greatly modify the scintillator responee. As can be seen from the parameters listed in Table 1 , the time resporse of the combination is limited primarily by the scintillatur. ${ }^{7}$ The peak, linear, output current of the stuorphotodiode is high, Elustantially greater then "'at of high-gain detectors.

\section{FAST FARADAY CUPS}

Coaxial Faraday cups designed to provide e"celletst time response have been used for some time. ${ }^{9}, 10$ A Faraday cup essentially transfers the incident electron pulse to the recording system via a coaxial cable with no energy selection and no charge gain. A gocd time response can be achieved by giving careful attention to impeciance matching. For such 2 . design, the :ecording system rather than the detector is the limiting factor in tirring measurements.

\section{Recording Systems}

Except for the tedious data reduction involved, the most satisfactory recording aystem for detector pulses in the nano- second range is the oscillossope. The oscilloscope trace is recorded on film, winch can be read accurately and provides 
both time information and a measure of detector charge output. Time-dependent backgrounds can be examined and appropriately substracted.

If pulse amplification is required, the most satisfactory device from the standpoint of wide range, time response, and linearity is the scope plug-in amplifier. Two types of systems are characterized in Table 2, one with a good time response in which the detector signal is coupled directly to the scope deflection plates, and one with greater sensitivity but poorer time response, in which a plug-in amplifier is used to permit coverege of a wide output-voltage range.

The time response of the scope is not a limiting factor for the detectors described above, except in the crie of the well-designed Faraday cup. If time information is not needed and timedependent backgrounds are not a problem. current integrators can be used to record pulse signals. A low-noise current integrating system has been developed at LLL ${ }^{11}$ covering a wide dynamic range, thus overcoming the main disadvantage of commercial systems.

Table 2, Recording systems.

\begin{tabular}{|c|c|c|c|}
\hline Oscilloscope & $\begin{array}{l}\text { Rise } \\
\text { time } \\
\text { (psec) }\end{array}$ & $\begin{array}{c}\text { Vertical } \\
\text { deflection } \\
\text { characteristics }\end{array}$ & $\begin{array}{l}\text { Input } \\
\text { impedance } \\
(\Omega)\end{array}$ \\
\hline \multirow[t]{2}{*}{ Tektronix 7904} & $(1.5 \mathrm{nsec})^{\mathrm{a}}$ & $10 \mathrm{mV} / \mathrm{div}$ & 50 \\
\hline & 350 & $\begin{array}{l}\text { Direct coupled } \\
4 \mathrm{~V} / \mathrm{div} .\end{array}$ & 50 \\
\hline Tektronix 519 & 350 & $10 \mathrm{~V} / \mathrm{div}$. & 125 \\
\hline EG\&G OS -40 & 200 & $200 \mathrm{~V}$ full scale & 100 \\
\hline $\begin{array}{l}\text { French Ferisol } \\
\text { Oz } 100 \mathrm{C}\end{array}$ & 150 & $\begin{array}{l}\text { Direct coupled } \\
\text { (in same range } \\
\text { as } O S-40 \text { ) }\end{array}$ & \\
\hline
\end{tabular}

\footnotetext{
Practical operating limit.
}

\section{Use of Flat Magnetic Spectrometers for Laser-Produced Plasmas}

We are currently measuring spectra of electrons emitted from laser-generated plasmas. In the production of fusion energy by laser-driven implosion, superthermal electron escape is one of the important energy-loss mechanisms. There is thus considerable interest in absolute eni: -4 measurements and angu- lar distributions of the emitted elec trons. ${ }^{12}$ Three characteristics of this measurement prescribe the use of a flat uniform-field spectrometer: (1) the electron current is high; (2) the spectrometer must view the source through a collimator external to a target chamber; and (3) because of a low pulse-repetition rate $(3$ 
pulses per hour to 1 pulse per dayl and variations in pulse characteristics, it is desirable to measure several energy channels simultaneously.

Expected spectrometer output signals for this experiment have been calculated based on the $x$-ray spectrum rneasurement of Slivinsky and Kornblum. 13,14 (They measured the $x$-ray energy output from a plasma produced by a $50-\mathrm{J}$ laser pulse and obtained a value of $5 \times 10^{7} \mathrm{keV}$ for tize integrated energy between 50 and $100 \mathrm{keV}$,) Finding that predicted electron-spectrometer signals were in a detectable range, we began plasma diagnostic measurements at the Long $P$ ath laser facility. A $90^{\circ}$-focusing spectrometer was obtained that, with sus iable detertors, covers a 6 - to $180-\mathrm{keV}$ energy range. It was necessary to use a rather sensitive recording systers based on Tektronix 7904 oscilloscopes. With available plug-in preamplifiers, we were abl: to measure the amplitude of the detector signals down to a level of $10 \mathrm{mV}$ before the noise became significant. These measurements will be described in more detail in a later report.

\section{Conclusion}

We conclude that flat, permanentmagnet, electron spectrometers are very suitable for spectral measurements of high-intensity, ronrepetitively pulsed sources. The channel resolution of a $180^{\circ}$-focusing spectrometer is sensitive to its entrance aperture dimensions, whereas that of a $90^{\circ}$-focusing spectrometer is sensitive to the divergence of the electrons from the suurce to aperture. Choice of the optimum design thus requires detailed analysis of the sourcespectrometer geometry. Of the available electron detectors, silicon semiconductors are very satisfactory and have been accurately calibrated between $30 \mathrm{keV}$ and several MeV. Anthracene or plastic scintillators coupled to photomultiplier tubes have been used at lower electron energies. Plastic scintillators coupled to photodiodes and Faraday cups may be considered fo: better time response. 


\section{References}

1. K. Siegbahn, ed., Alpha, Beta, and Gamma Ray Syectroscopy (North Holland Publishing Co., Amsterdam, 1965), Vol L., Chap. liL.

2. R. T. Brown, Elgerton, Germeshausen and Grier, Inc.. Las Vegas, Nev., unpublished calculations, private communication (1972),

3. R. H. Pehl, F, S. Goulding, D. A. Landis, and M. Lenzlinger, Nucl. instrum. Methods 59, 45 (1968).

4. R. W. Kuckuck, Semiconductor Detectors for Use in the Current Mode, Lawrence Livermore Laboratory, Rept, UCRL-51011 (1971).

5. M. J. Berger, S. M. Seltzer, S. C. Chappell, J. C. Humphreys, and J. W. Motz, Nucl. Instrum. Methods 69, 181 (1969).

6. F. T. Porter, M. S. Freedman, F. Wagn sr, Jr., and I. S. Sherman, Nucl. Instrum. Meiliods 39,35 (1966).

7. P. B. Lyons and J. Stevens, Nucl. Instrum. Methods 114, 313 (1974).

8. J. Stevens and L. P. Hocker, Time Response of an RCA C31024 Photomultiplier with High-Gain Gallium Phosphide Dynodes, Edgerton, Germeshausen and Grier, Inc., Las Vegas, Nev., Rept. 1183-2291 (1972).

9. P. J. Ebert and D. R. Lasher, Rev. Sci. Instrum. 37, 964 (1966).

10. N. J. Norris and R. K. Hanst, IEEE Trans, Nucl, Sci. NS-16, 27 (1969).

11. R. Lerche, Lawrence Livermore Lebnratory, private communication (1974).

12. Laser-Fusion Program Semiannual Report, July to Lecember 1973, Lawrence Livermore Laboratory, Rept. UCRL-50021-73-2 (1973),

13. V. W. Sliringky and $H$. N. Kormblum, Lawrence Livermore Labnratory, Rept. UOPE73-9 (1973).

14. V. W. Slivinsky, Lawrence Livermore Laboratory, private communication (1974). 


\section{Appendix A}

SPECTROMETER CHANNEL RESPONSE

Computer programs describing the performance of the $90^{\circ}$-focusing spectrometer were first developed at LIL by Delynn Clark and have been extensively refined by Lloyd Multhauf. The spectrometer design-code input is a detailed description of the spectrometer geometry. The input parameters include aperture dimensions, the finite extension of the source, a delailed description of the spectrometer magnetic field, and detector location. The output is the response of the apectrometer channel as a function of incident energy. The detector output current is also computed for a given input electron flux.

Each of the detector locations can be optimized with this code to obtain the desired electron center energy and the beat spatial electron-energy resolution. (The response function with the steepest sides corresponds roughly to optimum resolution.) The calculation involves a numerical integration in which both the source and the entrance slit are divided into small area elements. The code choc:es a weighted area element in the source and examines a ray of electrons originating from this element and passing through a selected area element in the entrance slit. The code traces the ray through a slit to the detector plane taking into account field nonuniformities (particularly those at the entrance $)$ and determines whether it passes within the entrance aperture of the detector under investigation.

All the rays from the source through the entrance slit are similarly examined. The, weights calculated for those rays incident on the detector are then summed to obtain the response of the spectrometer channel to electrons of energy E. An incremental change in the electron energy is made, and the calculation is repeated over the desired energy range.

Examples of the response vs energy determined for three different-sized detectors in a $90^{\circ}$-focusing spectrometer are shown in Fig. 4. The width of each

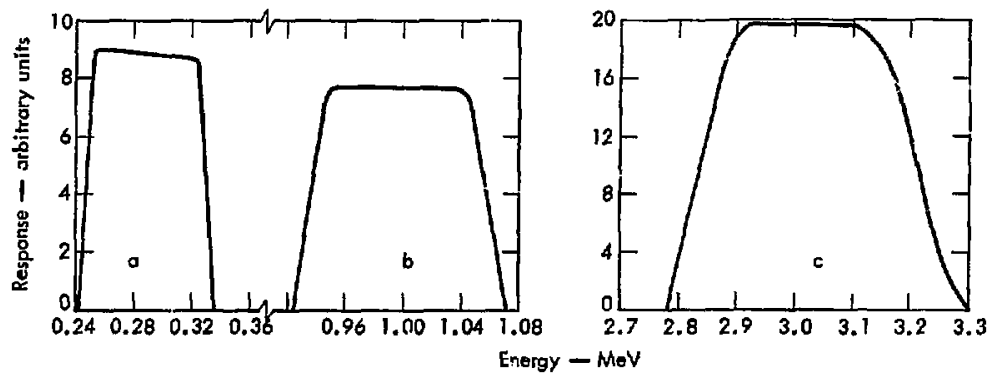

Fig. 4. Representative spectrometer channel-response functions with $90^{\circ}$ focusing. (a) $0.3-\mathrm{MeV}$ channel. (b) 1.0-MeV channel, (c) $3,0-\mathrm{MeV}$ channel. 
response curve is determined mainly by the width of the detector entrance aperture. The channel width $\Delta \mathrm{E}$ is taken to be be the full width at half maximum of the response curve. The flat top and steep sides of the $300-k e V$ response function indicate that the spatial electron-energy resolution is very good relative to the dimensions of the detector aperture. Note the change in slope of the sides of the response function with increasing energy. This is mainly due to the decrease of the spatial electron-energy resolution.

The determination of $\Delta \mathrm{E}$ is considered to be good to within $\pm 3 \%$ for each channel. Sources of error in the energy $E$ include

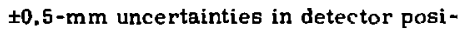
tloning and $2 \%$ uncertainties in the spectrometer magnetic field. The uncertainties lead to an estimated error in $\mathrm{E}$ of $3 \%$ for each spectrometer channel. 


\section{Appendix B}

SILICON DETECTOR

CALIBRATION

Silic on detectors were calibrated from $30 \mathrm{keV}$ to $4 \mathrm{MeV}$ in counting experiments using electron accelerators at L.LI, and NBS. Three calibration techniques were considered: pulse, direct-current, and counting methods. The first technique was ruled out because pulsed operation of the accelerators was not readily available. The dc method involved the measurement of the detector output current for a known incident, monoenergetic, electron-beam current. When this technlque was used with lithium-drifted silicon detectors, the observed detector output currents were found to be erroneously large because of a slow component contribution from the silicon dead layers. Therefora, dc measurements were made on the $p-i-n$ detector only to check the counting method, which was considered more relinble.

What we seek to deternine trum a counting measurement is the average energy depnsited in the active region of a detector per incident electron. Knowing Ac, we can then derlve the electron-flux inpul to a detcctor from the observed output curreat, using the faet that 3.67 $=0.02$ charge paira ars produced per clectron valt of energy deposited in atll. con. The technique involves pulae-height analysts of the detertor sutput charge. ${ }^{3}$ The ampltide of each output pulte te, of courtif. directly proportional to the emount of enerey deposited in the deteewr by the intident olectron.

Ficctron eurrents sultable for andiyzing silicon-delector pulse hatghis have been developed at Nas to envor wide energy range. ${ }^{5}$ Since a small input electron current is required to prevent piling up of pulses, the primary beam of the dc accelerator was scattered from a thin gold foil $\left(20\right.$ to $\left.30 \mu \mathrm{g} / \mathrm{cm}^{2}\right)$. The scattered electrons were collimated at an angle of $30^{\circ}$ with respect to the incident beam. Upon emerging through a port in the scattering chamber into an evacuated collimator assembly designed at LLL, the electrons were perpendicularly incident upon the face of the silicon detector. The detector was located in a collimator assembly similar to that used in the spectrometer. This assembly included an entrance aperture and a low $-Z$ backing to limit backscattering from transmitted eiectrons. A remote control arrangement was designed so that the absurber could be positioned to intercept the electron beam. The beam-interrupt mode was used to monitor background, the main suurce of which was brensstrahlung produced in the primary eloctron-beam trap.

The countung method was limited to those field detuctors avilable with chergs resplution suttable for pulseheight aralysis: in this cast, there were three snall ( $7 \times$ it $\left.\mathrm{mm}^{2}\right)$, (wo medium (B) $\times 1$ il $\left.\mathrm{mm}^{2}\right)$. and two targe $\left(20 \times 22 \mathrm{~mm}^{2}\right)$ deteclors. For a given detwertor and inctdent eleetron energy, a pulse-licight spectrum was obtained from whicl the obserwed background spectruns was sub. Iracled. The analyzar theray calibration wes made using inkwral conversion peak*

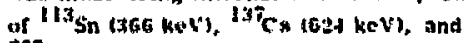
507 BI tofs kevt), Wheneter pasalble, the full denerty pook wot the waciros bram was 
also used. Thus the distribution of absorbed electron energy was obtained, from which the average, deposited, electron energy $\Delta \epsilon$ could be readily derived. The observed dependence of $\Delta \epsilon$ on the incident electron energy is shown in Fig. 5. The theoretical results, which were derived from Monte Carlo calculations of Berger and Seltzer, are shown for comparison.
As can be seen, good agreement between experiment and theory was obtained for the $0.2-\mathrm{mm}$ case at low energies. Here the principal cause for incomplete electron-energy deposition is backscattering of electrons from the front detector surface, a mechanism reasonably well understuod. However, for the $0.5-\mathrm{mm}$ detector, there is a gradual divergence of the observed $\Delta \epsilon$ from the

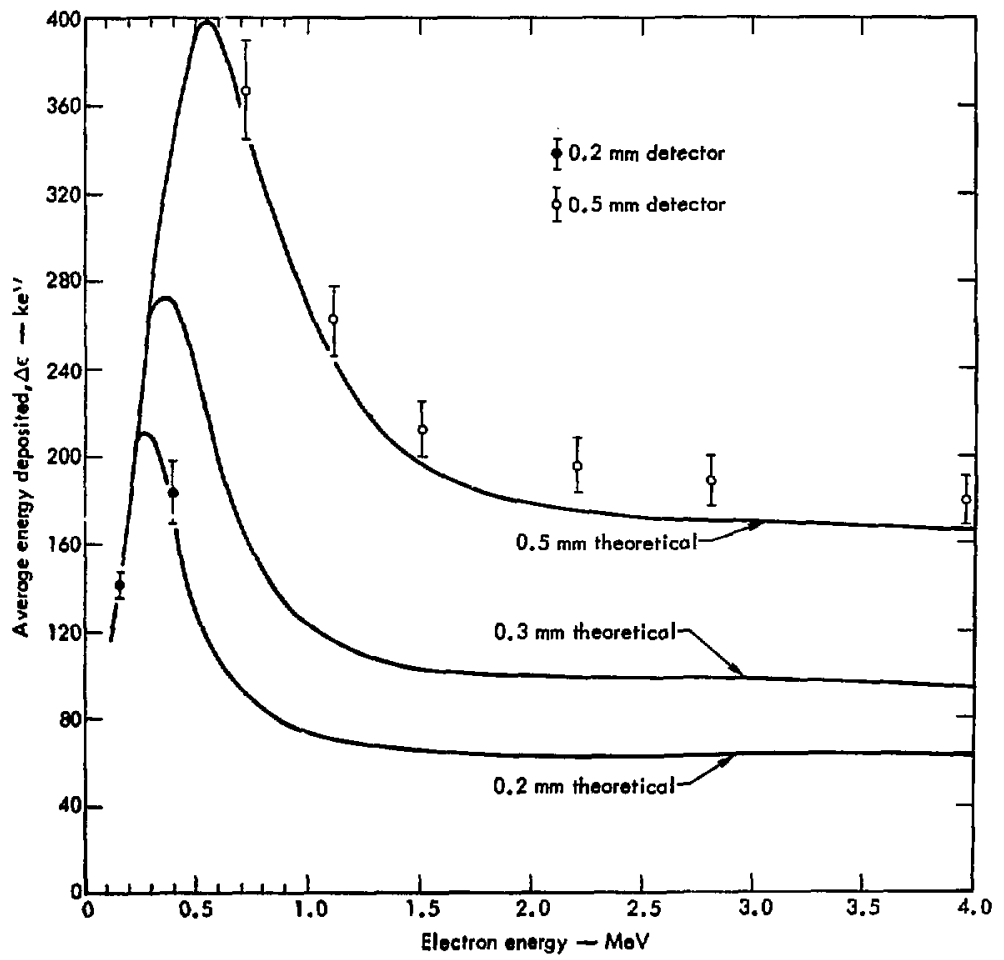

Fig. 5. Dependirce of the average, deposited, electron energy $\Delta \epsilon$ on the incident electron mergy. 
theoretical curve with increasing electron energy. Thus, greater energy absorption is observed at higher energies than is calculated. Apparently there are difficulties in handling electron straggling in the random walk calculation, resulting in too much transmission through the detector and hence not enough absorption.

Estimated errors incurred in the measurement of $\Delta \epsilon$ included uncertainties in detector thickness, incident beam energy, and analyzer energy callbration. Errors that could be neglected included those due to background subtraction, analyzer spectrum statistics, and analyzer nonlinearities. Effects due to the $1-\mu \mathrm{m}$ detector dead layers could also be neglected.

Detector thickness tolerance was $\pm 12.5 \mu \mathrm{m}$, resulting in uncertainties of $5 \%$ in $\Delta \epsilon$. For $150-\mathrm{keV}$ electrons, there was no error due to detector thickness variations, since the detector is totally absorbing (except for the reflected com ponent). Because the electron fullenergy peak could be used to help calibrate the analyzer, a substantial part of the error in $\Delta \epsilon$ at $150 \mathrm{keV}$ was from the uncertainty of the incident beam energy itself.

The absolute energy of the beam was known to within $2 \%$ for the 150-, 400-, and 700-keV electron energies, yielding errors in $\Delta \epsilon$ of $2 \%, 2 \%$, and $1.5 \%$, respectively.

In the broad transmigsion region above $2 \mathrm{MeV}$, the value of $\Delta \epsilon$ and the corresponding uncertainty were rather insensitive to the beam energy. The chief source of error Involved the analyzer calibration, since the electron fuli-energy peak could not be readily observed. By comparison, the 400- and 700-keV points were more sensitive to beam energy, but the analyzer calibrations were subject to less uncertainty.

The main factors to be considered in extending the results of this calibration to detectors that could not be calibrated include possible variations in the detector thickness and quality of the silicon used. The final errors were increased to take into account possible thickness variations based on information from the manufacturer.

At energies between 30 and $150 \mathrm{keV}$, for detector efficiency values we used the Monte Carlo results of Brown, which included the effects of energy loss in the detector dead layer and backscattering losses caused by electron-atom interactions. Experimental verification was obtained for 60 and $100 \mathrm{keV}$. These measurements were made at LLL with the sllicon detector assembly and using a low-energy ( $<100 \mathrm{keV}$ ) electron accelerator. Electrons were scattered from a thin gold foil to reduce the beam current adequately for a counting exper . inent. Monoenergetic electrons of energy determined by acceleration-tube voltage measurements were collimated into a $300-\mu \mathrm{m}$ detector having a dead layer of $0.5 \mu \mathrm{m}$. The measured spectrum included a noise contribution that increased rapidly below $20 \mathrm{keV}$. In this region, the electron response was generated by linearly extrapolating from the higher enerfy regions.

Experimental results at 60 and $100 \mathrm{keV}$ gave the same efficiency value of $91 \pm 3 \%$, which compares well with Brown's calculations of $93 \%$ and $90 \%$, The dominant contribution to the 
experimental error is from the extrapolation procedure.

Lower-energy efficiency values have not been yerified experimentally. Low energy measurements are inore difficult to make because of detector noise and errors produced by the increased gignificance of losses in the detector dead layer.

JKP/ $\mathbf{s} / \mathrm{lme}$

$-16$ 